\title{
ENHANCEMENT OF NATURAL CONVECTION HEAT TRANSFER FROM RECTANGULAR FINS BY CIRCULAR PERFORATIONS
}

\author{
Wadhah Hussein Abdul Razzaq Al- Doori \\ Technical Institute/Al-Door, Foundation of Technical Education, \\ Ministry of Higher Education and Scientific Research, Iraq \\ Iraq/Salah Al-din/ Al-door/ Technical institute/Al-door/ House No. 06. \\ Phone: 009647703964452 \\ E-mail:wadhahh@yahoo.com
}

\begin{abstract}
The importance of heat transfer by natural convection in enclosures can be found in many engineering applications, such as energy transfer in buildings, solar collectors, nuclear reactors and electronic packaging. An experimental study was conducted to investigate heat transfer by natural convection in a rectangular fin plate with circular perforations as heat sinks. The patterns of the perforations included 24 circular perforations (holes) for the first fin; the number of perforations increased by eight for each fin to 56 in the fifth fin. These perforations were distributed in 6-14 rows and four columns. Experiments were carried out in an experimental facility that was specifically designed and constructed for this purpose. It was observed that the temperature along the non-perforated fin dropped from 30 to $25^{\circ} \mathrm{C}$, but the temperature drop for the perforated fins was from 30 to $23.7^{\circ} \mathrm{C}$ at low power $(6 \mathrm{~W})$. The drop in temperature between the fin base and the tip increased as the diameter of the perforations increased. The temperature drop at the highest power $(220 \mathrm{~W})$ was from 250 to $49^{\circ} \mathrm{C}$ for the nonperforated fin and from 250 to $36^{\circ} \mathrm{C}$ for the perforated fins. The heat transfer rate and the coefficient of heat transfer increased with an increased number of perforations.
\end{abstract}

Keywords: Natural convection; temperature distribution; circular perforated fins.

\section{INTRODUCTION}

For a number of industrial applications, heat generation can cause overheating which occasionally leads to system failure. To overcome this problem, efficient heat sinks are essential. Free convection from these devices is a commonly used cooling technique and plays an important function in preserving proper operation. Extended surfaces, known as fins, are typically used to enhance heat transfer in many industries. The performance of heat exchanging devices can be increased by applying extended surfaces. Practical applications of this technique are found in some heat exchangers used for cooling combustion chambers and electronic devices (Kern and Kraus, 1972; Kraus and BarCohen, 1983). Using fins as extended surfaces increases the weight and volume of the device and also increases the cost of production. As a result, in recent years, much care has been taken in optimising fin geometry.

Advanced technologies need superior heat transfer equipment. Processes for improving heat transfer are classified into two families: active and passive methods (Bergles, 2001). Active methods need an external power source to enhance heat transfer, but passive methods do not need an external power source. Fins are a good example of a passive method, and they are typically applied in an assortment of 
industrial applications to enhance the rate of heat transfer between the primary surface and the ambient fluid (Shaeri et al., 2009).

Fins as heat transfer enhancement devices have become quite common. As extended surface technology continues to grow, new design ideas come forth, including fins made of anisotropic composites, porous media as well as perforated and interrupted plates (Bayram and Alparslan, 2008). Due to the requirement for lightweight, compact and economical fins, the optimisation of fin size is important. Consequently, fins must be designed to achieve maximum heat removal with minimum material expenditure, thereby facilitating manufacture of the fin (Al-Essa and Al-Hussien, 2004). Many studies have investigated optimising fin shapes. Other studies have introduced shape adjustments by cutting some material from the fins to make cavities, holes, slots, grooves or channels through the fin body to increase the heat transfer area and/or the heat transfer coefficient (Elshafei, 2010).

One popular heat transfer augmentation technique involves the use of interrupted surfaces in different configurations. The interruption aims at promoting surface turbulence and is mainly intended to increase the heat transfer coefficient of the surface area (Kutscher, 1994). It has been reported that non-flat surfaces have natural convection coefficients that are $50 \%$ to $100 \%$ greater than those of flat surfaces (Chung and Iyer, 1993). Many other researchers have reported a similar trend for interrupted, perforated and serrated surfaces, attributing the improvement to restarting the thermal boundary layer after each interruption, indicating that the increase in the convection coefficient is more than enough to offset the area lost, if any (Elshafei, 2010). A straight fin's concave parabolic profile provides maximum heat dissipation for a given profile area (Malekzadeh et al., 2006). For most applications, rectangular fins are used to reduce the cost of manufacturing. Based on the widespread application of rectangular fins that are normally used for heat exchangers, an understanding of the convection mechanisms and a prediction of the heat transfer performance of rectangular fins is important. These parameters are commonly analysed simultaneously by flow and heat transfer (Suksangpanomrung et al., 2007). Mousa (2000) theoretically analysed the thermal performance for a horizontal rectangular fin with a uniform cross-sectional area embedded with four vertical body perforation patterns that extended through the fin. The investigated patterns included triangular, square, circular and rectangular perforations. Natural convection with the finite element technique was used to analyse these patterns. The analysis showed that the heat transfer of the perforated fins was greater than that of the non-perforated fin.

Heat transfer from extended surfaces for a given fin material, base temperature and ambient temperature can be enhanced by increasing the heat transfer coefficient and by increasing the effective heat transfer surface area (Shaeri and Yaghoubi, 2009). The heat transfer coefficient of the fin surface can be increased by introducing surface roughness and hence promoting turbulence. As for the surface area, the literature has introduced several methods to increase the effective heat transfer surface area of fins (Abdullah and Mohammed, 2009). This paper focuses on investigating the effect of increasing the number of perforations on the distribution of temperature, the heat transfer rate and the coefficient of heat transfer.

\section{MATHEMATICAL ANALYSIS OF PERFORATED FINS}

Perforated fins can be used to increase the heat transfer coefficient and effective heat transfer area. The change in the magnitude of the surface area depends on the geometry 
of the perforations (Abdullah and Mohammed, 2009). In this paper, the number of perforations $N_{x}$ in the $x$ direction $(L)$ and $\mathrm{N}_{\mathrm{y}}$ in the $y$ direction $(W)$ were assumed as shown in Figure 2. The perforation cross-sectional area $\left(A_{c}\right)$ was assumed and then the dimensions of the perforations were calculated. The surface area of the uniform longitudinal rectangular perforated fin can be expressed as follows:

$$
\begin{gathered}
A_{f p}=A_{p s}+A_{t}+N_{c} A_{p c} \\
A_{f p}=\left(2 W \cdot L-2 N_{c} \cdot A_{c}\right)+(W \cdot t)+\left(N_{c} \cdot A_{c}\right) \\
A_{f p}=A_{f}+N_{C}\left(A_{p c}-2 A_{c}\right)
\end{gathered}
$$

Equation (3) can be written as Eq. (4):

$$
A_{f p}=A_{f}+N_{x} \times N_{y}\left(A_{p c}-2 A_{c}\right)
$$

In order to compare the heat transfer surface area of the perforated fin $\left(A_{f p}\right)$ to that of the conventional fin $\left(A_{f}\right)$, the fin surface area ratio $(R A F)$ was introduced as given by Eq. (5).

$$
\begin{gathered}
R A F=\frac{A_{f p}}{A_{f}} \\
R A F=1+\frac{N_{x} \times N_{y}\left(A_{p c}-2 A_{c}\right)}{A_{f}}
\end{gathered}
$$

The material volume of the perforated fin as compared with the volume of the non- perforated fin is given by the volume reduction ratio $(R V F)$ which is expressed as Eq. (7):

$$
\begin{gathered}
R V F=\frac{V_{f p}}{V_{f}}=\frac{\left(L \times W \times t-N_{x} \times N_{y} \times A_{c} \times t\right)}{L \times W \times t} \\
R V F=1-\frac{N_{x} \times N_{y} \times A_{c}}{L \times W}
\end{gathered}
$$

Similarly, the perforated fins had less weight than the equivalent non-perforated fin. This aspect was expressed by the fin weight reduction ratio $(R W F)$ defined as Eq. (9):

$$
\begin{array}{r}
R W F=\frac{W_{f p}}{W_{f}}=\frac{\left(W_{f}-N_{x} \times N_{y} \times A_{c} \times t \times \rho\right)}{W_{f}} \\
R W F=1-\frac{\left(N_{x} \times N_{y} \times A_{c} \times t \times \rho\right)}{L \times W \times t \times \rho}=1-\frac{N_{x} \times N_{y} \times A_{c}}{L \times W}
\end{array}
$$

In terms of the shape and dimensions of the perforations cut from the fin body, fins with circular perforation patterns were studied. The number of perforations in the longitudinal direction is given as $N_{x}$, in the transverse direction as $N_{y}$ and the perforation diameter is $b$. The directional perforation spacings $S_{x}$ and $S_{y}$ are given as:

$$
L=N_{x} \cdot b+\left(N_{x}+1\right) S_{y}
$$




$$
\begin{gathered}
S_{x}=\frac{L-N_{x} \cdot b}{N_{x}+1} \\
W=N_{y} \cdot b+\left(N_{y}+1\right) S_{y} \\
S_{y}=\frac{W-N_{y} \cdot b}{N_{y}+1}
\end{gathered}
$$

The heat transfer surface area of the fin can be expressed as Eq. (15):

$$
\begin{gathered}
A_{f p}=A_{f}-2 N_{c} \cdot A_{c}+N_{c} \cdot A_{p} \\
A_{f p}=A_{f}+N_{c}\left(A_{p}-2 A_{c}\right)=A_{f}+\pi N_{C} \cdot b\left(t-\frac{b}{2}\right)
\end{gathered}
$$

The $R A F$ and $R V F$ can be expressed as Eq. (17) and Eq. (18), respectively:

$$
\begin{array}{r}
R A F=1+\frac{\pi \times b \times N_{x} \times N_{y}\left(t-\frac{b}{2}\right)}{(2 W \times L+W \times t)} \\
R V F=1-\frac{N_{x} \times N_{y} \times \frac{\pi}{4} b^{2}}{L \times W}
\end{array}
$$

An experimental correlation to estimate the convection heat transfer coefficient of an array of vertically oriented parallel flat plates is given by Eq. (19) (Mousa, 2000).

$$
N u=\frac{h \times B}{k}=\frac{R a}{24}\left(1-e^{\frac{-35}{R a}}\right)^{0.75}
$$

where $B$ is the average space between adjacent fins.

$$
R a=\frac{\rho^{2} \times g \times \beta \times C_{p} \times B^{4} \times \Delta T}{\mu \times k \times L}
$$

Several studies (Abdullah and Mohammed, 2009; Mousa, 2000) have reported that the surface heat transfer coefficient of perforated surfaces is a function of the open area ratio $(R O A)$ of the perforated surface. The open area ratio is defined as Eq. (21):

$$
R O A=\frac{O A}{O A_{\max }}
$$

where $O A$ is the actual open area $=A_{c} \cdot N_{c}$

$$
O A=A_{c} \cdot N_{x} \cdot N_{y}
$$

$O A_{\max }$ is the maximum possible perforation open area, which is defined as Eq. (23)

$$
O A_{\max }=A_{c} \cdot N_{c, \text { max }}=A_{c} \cdot N_{x, \max } \cdot N_{y, \max }
$$


where $N_{x, \max }$ and $N_{y, \max }$ are the maximum possible number of the perforations along the fin. These numbers related to a perforation spacing equalling zero. The perforated surface heat transfer coefficient ratio $\left(R_{h}\right)$ can be expressed as Eq. (24) (Shaeri and Yaghoubi, 2009).

$$
R_{h}=1+0.75 \frac{O A}{O A_{\max }}
$$

The film heat transfer coefficient of the perforated surface $\left(h_{p s}\right)$ is expressed as Eq. (25):

$$
h_{p s}=\left(1+0.75 \frac{O A}{O A_{\max }}\right) h
$$

\section{EXPERIMENTAL DETAILS}

The experiments were carried out in an experimental facility that was specifically designed and constructed for this purpose. Figure 1 shows a view of the experimental apparatus. The experimental setup included a heat sink supplied with heating elements and a data acquisition system. Heat was generated within the heat sink by means of one heating element with a power of $670 \mathrm{~W}$. All the experimental data were recorded by the data acquisition system. The heat sink chosen for these experiments was an aluminium cylinder $50.8 \mathrm{~mm}$ in diameter and $270 \mathrm{~mm}$ in length (Figure 2). One hole was drilled in the cylinder in which one heating element was placed. Five aluminium straight fins were fitted radially. The fins were $100 \mathrm{~mm}$ long, $270 \mathrm{~mm}$ wide and $2 \mathrm{~mm}$ thick. These fins were divided into five groups as shown in Table 1.

Table 1: Five types of perforated fins, their diameters and the number of perforations per fin

\begin{tabular}{ccc}
\hline Fin & Perforated fin diameter $(\mathbf{m m})$ & Number of perforations per fin \\
\hline 1 & 12 & 24 \\
2 & 12 & 32 \\
3 & 12 & 40 \\
4 & 12 & 48 \\
5 & 12 & 56 \\
\hline
\end{tabular}

A variable transformer of type $50 \mathrm{~B}$ with an input of $220 \mathrm{~V}$ at $50-60 \mathrm{~Hz}$ and an output of $0-240 \mathrm{~V}$, at $20 \mathrm{~A}$ and $7.5 \mathrm{kVA}$, was used to regulate the voltage supplied to the heating element (Figure 2). The experimental data were measured by 27 calibrated type-K thermocouples to measure the temperature at different locations. The measured parameters and their ranges during the experiments were as follows:

1. Heat supplied: 6-220 W.

2. Perforation shape: circular.

3. Number of perforations: 24 to 56 . 
One thermocouple was fixed on the outside of the aluminium cylinder to measure the base temperature of the fin. One thermocouple was used to measure the air temperature. The remaining 25 thermocouples were divided equally onto the five fins. Each thermocouple was fixed to the surface of the test fin with equal spacing $(20 \mathrm{~mm})$ along the fin length. The apparatus was allowed to run for about 70 minutes until the steady state was achieved. The recording of temperature began after the steady state had been reached.

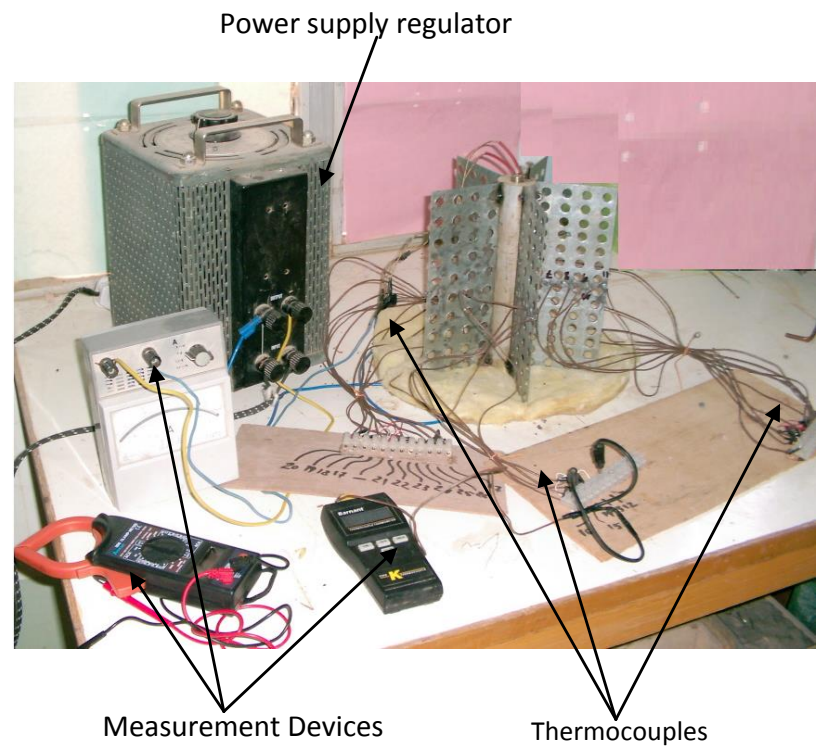

Figure 1. Experimental apparatus

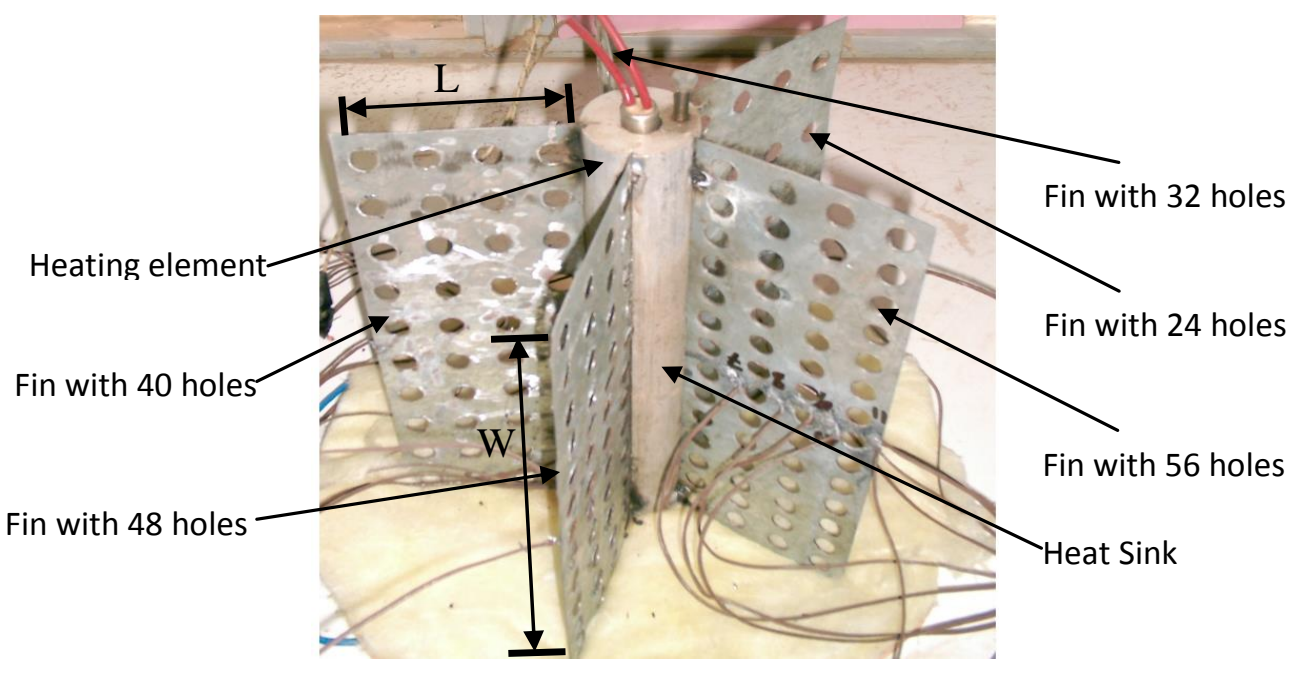

Figure 2. View of the heat sink

\section{RESULTS AND DISCUSION}

Studies that have investigated perforation shape geometry indicate that increases or decreases in the surface area of the perforated fin with respect to non-perforated fins depend on the following parameters: the fin thickness, the total number of perforations, $N_{c \text {; }}$ and the perforation diameter, $b$. However, whether $A_{f p}$ is greater or smaller than $A_{f}$ 
depends on the fin thickness and perforation diameter. The calculations show that the heat transfer surface area of the perforated fin is a function of the fin dimensions and the perforation shape geometry. The temperature distributions of the perforated fins and the non-perforated fin along $x$ direction are plotted in Figure 3. As shown in the figure, it is obvious that the temperature distribution along the non-perforated fin was greater than that of the perforated fins in most cases. The results also indicate that the temperature drop between the fin base and the tip increased as the perforation diameter increased. This was because the thermal resistance of the perforated fin decreased as the perforation diameter increased.

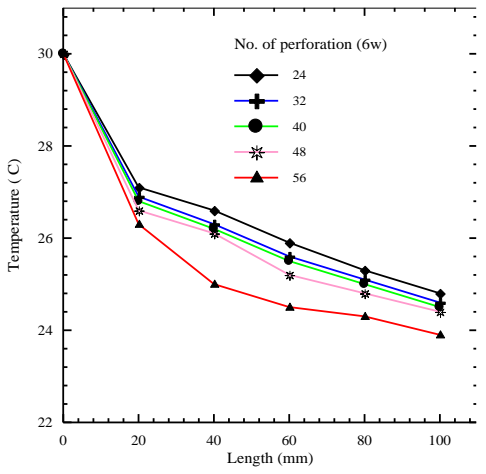

(a) $6 \mathrm{~W}$

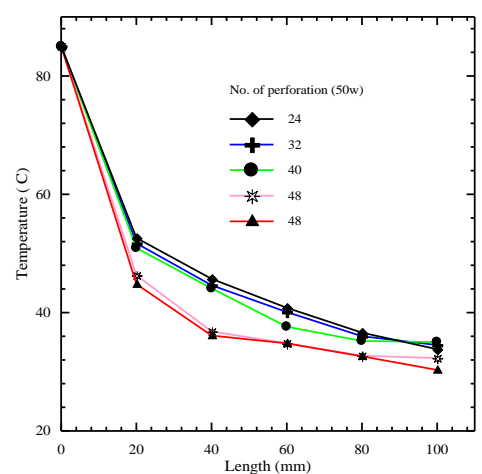

(d) $50 \mathrm{~W}$

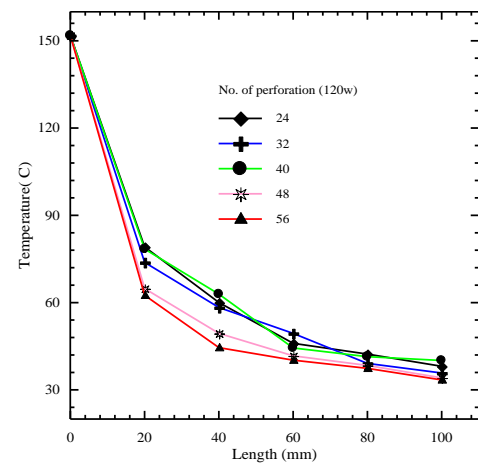

(g) $120 \mathrm{~W}$

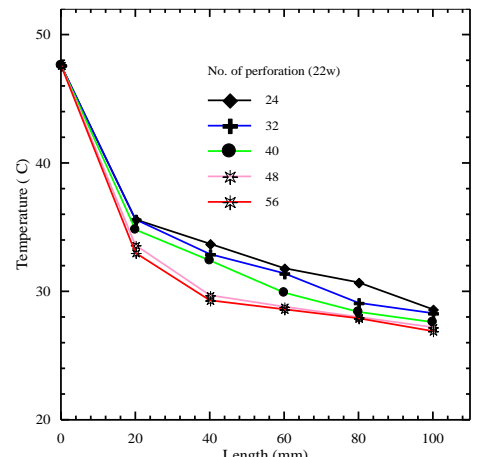

(b) $22 \mathrm{~W}$

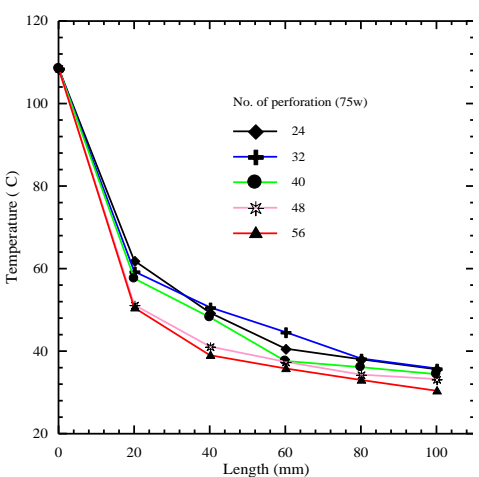

(e) $75 \mathrm{~W}$

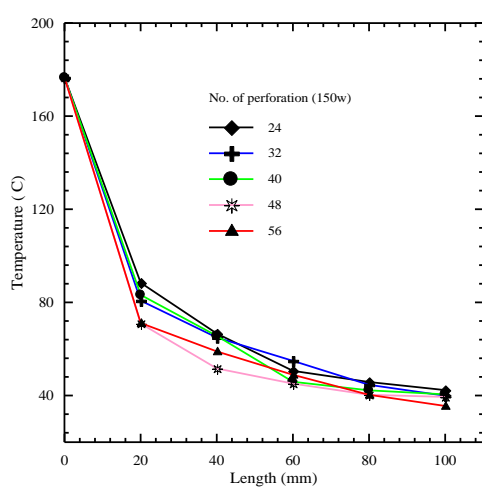

(h) $150 \mathrm{~W}$

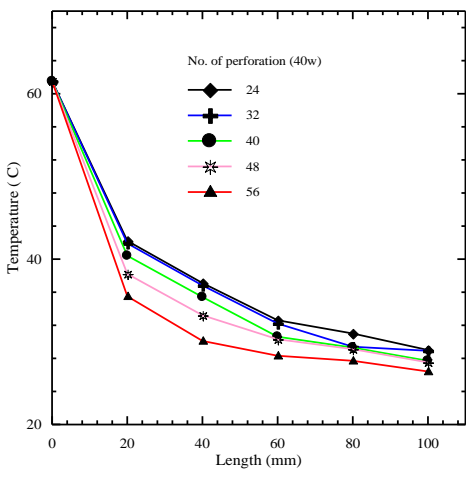

(c) $40 \mathrm{~W}$

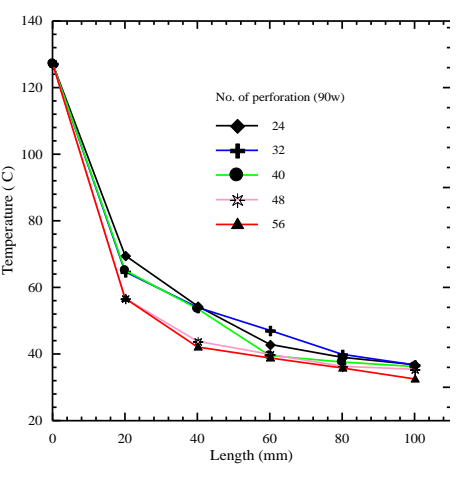

(f) $90 \mathrm{~W}$

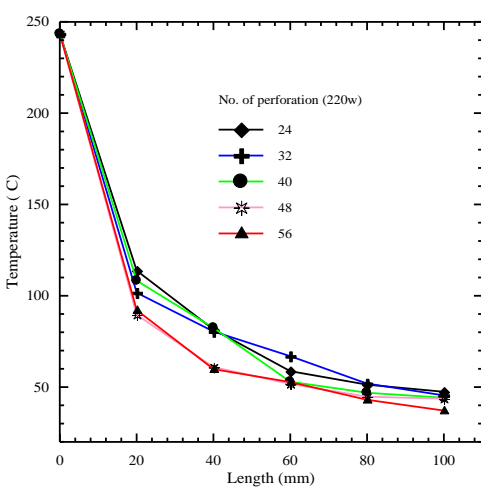

(i) $220 \mathrm{~W}$

Figure 3. The temperature distribution of the perforated and non-perforated fins in the $x$ direction 
The data indicate that $R A F$ was a weak function of the fin length and width. This occurred because the effect of the fin tip area can be neglected. The temperature distribution along the fin has an important effect on fin performance. Higher fin temperatures are seen when the fin's thermal resistance is decreased.

Figure 4(a) shows the relationship between $R A F$ and the number of perforations. This figure shows that $R A F$ was smaller than unity. The heat dissipation rate of a perforated fin depends on the heat transfer coefficient and fin area. In this study, all the film heat transfer coefficients were assumed to be uniform and equal. It was mentioned before that $R_{h}$ is always greater than unity. In this study, $R_{h}$ increased to the upper limit of 1.25 as the number of perforations increased. However, this value decreased to the lower limit of 1.1. The calculation of $R_{h}$ is plotted against the number of perforations in Figure 4(b). The ratio $R W F$ is plotted as a function of the number of perforations in Figure 4(c). The figure shows that the weight reduction ratio of the perforated fin continued to decrease as the number of perforations increased. Figure 5 shows the relationship between the film heat transfer coefficient of the perforated surface $\left(h_{p s}\right)$ and the number of perforations at different power levels. The film heat transfer coefficient increased with an increase in both the number of perforations and the power.

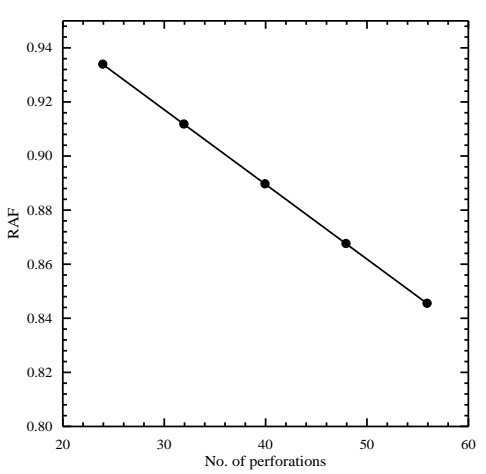

(a) $R A F$

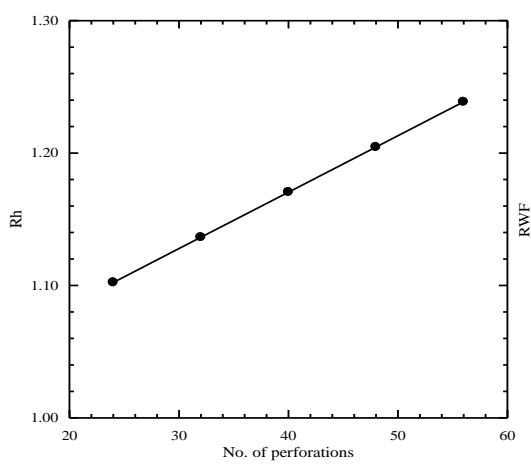

(b) $R_{h}$

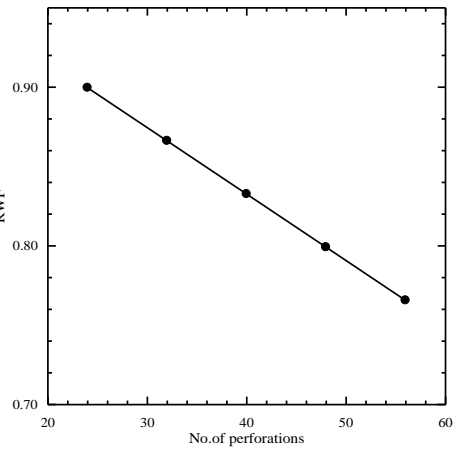

(c) $R W F$

Figure 4. The relationship between $R A F, R_{h}, R W F$ and the number of perforations.

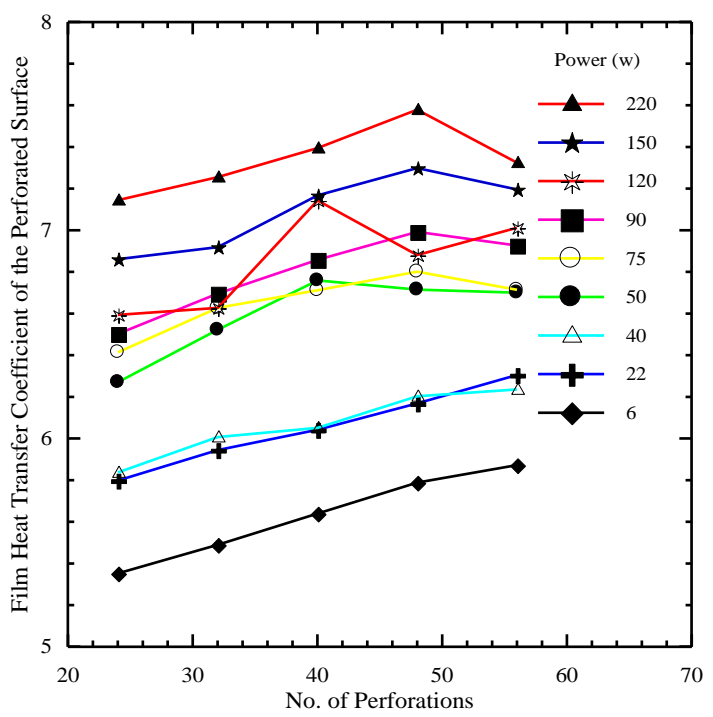

Figure 5. The relationship between $h_{p s}$ and the number of perforations at various power levels. 


\section{CONCLUSION}

The temperature drop along the length of the perforated fins was consistently higher than for the equivalent non-perforated fin. The increase in the heat dissipation rate for the perforated fin was strongly dependent on the perforation dimensions and lateral spacing. Decreasing the perforation dimensions reduced the rate of temperature drop along the perforated fin. The heat transfer coefficient for the perforated fin with a larger number of perforations was greater than for the perforated fin with a small number of perforations.

\section{REFERENCES}

Abdullah, H. Al. and Mohammed Q. A., 2009. Enhancement of natural convection heat transfer from a fin by triangular perforations of bases parallel and toward Its base. The Arabian Journal for Science and Engineering, 34(2B): 531-544.

Al-Essa, A.H. and Al-Hussien, F.M.S. 2004. The effect of orientation of square perforations on the heat transfer enhancement from a fin subjected to natural convection. Heat and Mass Transfer, 40: 509-515.

Bayram, S. and Alparslan D., 2008. Performance analysis of a heat exchanger having perforated square fins. Applied Thermal Engineering, 6: 621-632.

Bergles, AE. 2001. The implications and challenges of enhanced heat transfer for the chemical process industries. Chemical Engineering Research and Design, 79(4): 437-444.

Chung, B.T.F. and Iyer, J.R. 1993. Optimum design of longitudinal rectangular fins and cylindrical spines with variable heat transfer coefficient. Heat Transfer Engineering, 14: 31-42.

Elshafei, E.A.M. 2010. Natural convection heat transfer from a heat sink with hollow/perforated circular pin fins. Energy, 35: 2870-2877.

Kern, D.Q. and Kraus, A.D. 1972. Extended surface heat transfer. New York: McGrawHill, 1972.

Kraus, A.D. and Bar-Cohen, A. 1983. Thermal analysis and control of electronic equipment. Washington: Hemisphere Publication Corporation.

Kutscher, C.F. 1994. Heat exchange effectiveness and pressure drop for air flow through perforated plates with and without crosswind. Journal of Heat Transfer, 116: 391-399.

Malekzadeh, P., Rahideh, H. and Karami, G. 2006. Optimization of convectiveradiative fins by using differential quadrature element method. Energy Conversion and Management, 47:1505-14.

Mousa, A.H. 2000. Enhancement of thermal performance of fins subjected to natural convection through body perforation. PhD. Thesis, Mechanical Engineering, Baghdad University, Iraq.

Shaeri, M.R. and Yaghoubi, M. 2009. Thermal enhancement from heat sinks by using perforated fins. Energy Conversion and Management, 50: 1264-1270.

Shaeri, M.R., Yaghoubi, M. and Jafarpur, K. 2009. Heat transfer analysis of lateral perforated fin heat sinks. Applied Energy, 86: 2019-2029.

Suksangpanomrung, A., Chungpaibulpatana, S. and Promvonge, P. 2007. Numerical investigation of heat transfer in pulsating flows through a bluff plate. International Communications in Heat and Mass Transfer, 34: 829-37. 